\title{
Correction to: The Downstream Impacts of Hydropower Dams and Indigenous and Local Knowledge: Examples from the Peace-Athabasca, Mekong, and Amazon
}

\author{
Ian G. Baird $\mathbb{1}^{1} \cdot$ Renato A. M. Silvano ${ }^{2} \cdot$ Brenda Parlee $^{3} \cdot$ Mark Poesch $^{3} \cdot$ Bruce Maclean $^{4} \cdot$ Art Napoleon $^{5}$. \\ Melody Lepine $^{6} \cdot$ Gustavo Hallwass $^{7}$
}

Published online: 17 February 2021

(c) Springer Science+Business Media, LLC, part of Springer Nature 2021

Correction to: Environmental Management

https://doi.org/10.1007/s00267-020-01418-x

In the original publication, the author "Bruce Maclean" was not included in the author group. The correct list of authors and the correct affiliations are published with this correction.
Acknowledgements This paper has emerged from a collaboration associated with the project, Tracking Change: Local and Traditional Knowledge in Watershed Governance which was funded by the Social Sciences and Humanities Research Council (SSHRC) of Canada in a grant to Parlee-University of Alberta (SSHRC PG 895-2015-1024 Parlee). R.A.M. Silvano also acknowledges research grants from the Conselho Nacional de Desenvolvimento Científico e Tecnológico (CNPq, grant 303393/2019-0) and from the Coordenação de Aperfeiçoamento de Pessoal de Nível Superior (CAPES-PRINT, grant 88887.467553/2019-00).
The original article can be found online at https://doi.org/10.1007/ s00267-020-01418-x.

Ian G. Baird

ibaird@wisc.edu

1 Department of Geography, University of Wisconsin-Madison, Madison, WI, USA

2 Departamento de Ecologia e Programa de Pós-Graduação em Ecologia-IB, Universidade Federal do Rio Grande do Sul (UFRGS), Porto Alegre, Rio Grande do Sul, Brazil

3 University of Alberta, Edmonton, AB, Canada

4 Maclean Environmental Consulting, Winnipeg, MB, Canada

5 Saulteau First Nations, Treaty 8 Territories, Moberly Lake, BC, Canada

6 Mikisew Cree First Nation Government and Industry Relations, Fort McMurray, AB, Canada

7 Universidade Federal do Oeste do Pará, Oriximiná, Brazil 